\title{
Effect of Non-aqueous Solvents on the Rate of Production of Copper Powder from Copper Sulphate Solution by Cementation on Stationary Zinc Sheet and Rotating Zinc Cylinder
}

\author{
A.A.Taha* \\ Department of Chemistry, Faculty of Science, University of Alexandria, Alexandria, Egypt.
}

Received 12 December 2002; accepted in revised form 2 March 2004

\begin{abstract}
The rate of copper II/zinc cementation from copper sulphate solutions in the absence and in the presence of methanol $\left(\mathrm{CH}_{3} \mathrm{OH}\right)$ and dimethyl sulphoxide (DMSO) has been studied and the reaction was found to follow first-order kinetics. The influence of several parameters on the course of the reaction, such as cylinder rotation speed, initial concentration of $\mathrm{Cu}^{2+}$ ions, temperature and concentration of organic solvent, was investigated. In the case of $\mathrm{CH}_{3} \mathrm{OH}$, rotating zinc cylinder was used, while in the presence of DMSO stationary zinc sheet and rotating zinc cylinder were used. It was found that (1) the percentage inhibition caused by methanol ranged from 10.70 to 58.38 depending on the concentration of the alcohol used; (2) the rate of cementation in the presence of DMSO using rotating zinc cylinder $>$ the rate of cementation in the presence of DMSO using stationary zinc sheet; (3) the rate of cementation on zinc cylinder in the presence of DMSO $<$ the rate of cementation in the presence of $\mathrm{CH}_{3} \mathrm{OH}$. Different reaction conditions, and the physical properties of solutions are studied to obtain dimensionless correlation among all these parameters. Thermodynamic parameters $\Delta \mathrm{S}^{*}, \Delta \mathrm{H}^{*}$ and $\Delta \mathrm{G}^{*}$ were studied.
\end{abstract}

Keywords: Cementation, methanol, dimethyl sulphoxide, rotating zinc cylinder.

\section{Introduction}

Cementation is used as a general term to describe the process whereby a metal is precipitated from a solution of its salt by another more electropositive metal. Such reactions have been, and are being, used extensively in the mineral

\footnotetext{
${ }^{*}$ Corresponding author. E-mail address: vegfruexp@yahoo.com
} 
industry, both for the recovery of metals (e.g. the extraction of copper from leach streams with iron) and for the purification of process streams (e.g. the removal and recovery of copper and cadmium from zinc sulphate electrolyte with metallic zinc). These processes have been in practical use for a considerable time [1-2] and the ultimate equilibria can be defined thermodynamically. However, since actual yield and process efficiencies are determined by rate factors, the knowledge of the reaction kinetics is essential for the most economic utilization of the process. Factors affecting these kinetics, such as geometry of the less noble metal surface, temperature, concentration of the metal ions and mode of stirring velocity, have been studied extensively [3-13]. An electrochemical nature of the cementation reaction was recognized and this pictured cementation to occur through shorted electrochemical cells similar to the model proposed for aqueous corrosion. The aim of the present work is to study the effect of non-aqueous solvents on the rate of cementation of copper from copper sulphate. $\mathrm{CH}_{3} \mathrm{OH}$ and DMSO are used as the organic solvent component to investigate the extent to which protic solvent as $\mathrm{CH}_{3} \mathrm{OH}$ and aprotic solvent as DMSO affect the rate of cementation reaction using rotating zinc cylinder. DMSO has some varieties and similarities in its behaviour with $\mathrm{CH}_{3} \mathrm{OH}$; therefore, the results can be easily compared with each other. The rate of cementation of $\mathrm{Cu}$ ion from $\mathrm{CuSO}_{4}$ dissolved in $\mathrm{CH}_{3} \mathrm{OH}-\mathrm{H}_{2} \mathrm{O}$ and DMSO- $\mathrm{H}_{2} \mathrm{O}$ media of different composition and at different temperatures was investigated in order to judge the role of these solvents on copper cementation and to correlate the thermodynamic parameters of activation. Rotating cylinder was used as a mean of enhancing the rate of cementation. Comparison with cementation studies in unstirred system was done. Different reaction conditions such as speed of rotation of the rotating zinc cylinder, physical properties of solution such as density, viscosity and diffusion coefficient, are studied to obtain a dimensionless correlation among all these parameters.

\section{Experimental}

Materials: $\mathrm{CH}_{3} \mathrm{OH}$ and DMSO were purified as previously reported [14,22]. 


\section{The apparatus}

\section{Case of stationary zinc sheet}

The apparatus used consists of a $500 \mathrm{~mL}$ glass beaker containing $400 \mathrm{~mL} \mathrm{CuSO}_{4}$ solution or $\mathrm{CuSO}_{4}$ - DMSO mixture in which zinc sheet of $9 \mathrm{~cm}$ length and $5 \mathrm{~cm}$ width is immersed. Before each run, the zinc sheet was degreased with trichloroethylene, etched in dilute $\mathrm{HCl}$ to remove oxides, washed with distilled water and dried. Five different solutions of copper sulphate with concentrations $6.25,31.75,63.56,95.25$ and $127 \mathrm{ppm}$ were used. $0.1 \mathrm{~mL}$ were taken from $\mathrm{CuSO}_{4}$ solution every 10 minutes and diluted to $10 \mathrm{~mL}$; this step is repeated for time intervals $10,20,30 \ldots$ up to 90 minutes.

\section{Case of rotating Zn cylinder}

The apparatus used permits the rotation of clamping $\mathrm{Zn}$ cylinder assembly arranged in such a way that only the peripheral surface of $\mathrm{Zn}$ (purity $>99.99 \%$ ) was exposed to the solution. The cylinder used has a length of $7 \mathrm{~cm}$ and a diameter of $1.4 \mathrm{~cm}$. Before each run, $\mathrm{Zn}$ cylinder was insulated to a length of 3 $\mathrm{cm}$ with polystyrene lacquer and the active surface of $\mathrm{Zn}$ was polished with fine emery paper, degreased with trichloroethylene, washed with alcohol and finally rinsed in distilled water. The cylinder was rotated in experimental solution by a laboratory stirrer, and its angular velocity monitored by means of an optical tachometer. The use of a rotating cylinder ensures that the hydrodynamics of the system are reproducible. The reaction vessel was set in a constant \pm 0.05 ultrathermostate.

The reaction vessel used consists of a $400 \mathrm{~mL}$ glass beaker containing $200 \mathrm{~mL}$ $\mathrm{CuSO}_{4}$ solution or $\mathrm{CuSO}_{4}$ organic solvent in which rotating cylinder is immersed. Five different media of different compositions $(5-30 \% \mathrm{v} / \mathrm{v})$ were used, where the concentration of $\mathrm{CuSO}_{4}$ was kept constant (31.75 ppm). The rate of cementation of copper on zinc metal was determined at different rotations (50, 100, 200, 300, 400, $500 \mathrm{rpm}$ ) and different temperatures. All chemical analysis were carried out using Perkin Elmer atomic absorption spectrophotometer. The density and viscosity of the different media studied were used to calculate the dimensionless groups Sherwood (Sh), Schmidt (Sc) and Reynolds (Re). The density was 
obtained using a DA.300 Kyoto electronic instrument. The viscosity was measured using koehler viscosity Bathing (model K 23400 kinematic Baths). The diffusion coefficients of copper ions in mixed solvents were measured by the capillary tube method.

\section{Results and Discussion}

The rate of diffusion-controlled cementation of $\mathrm{Cu}^{2+}$ ions on stationary sheet or rotating zinc rod can be expressed in terms of the disappearance of cupric ions from the solution by the relation.

$$
\mathrm{Zn}+\mathrm{Cu}^{2+} \rightarrow \mathrm{Zn}^{2+}+\mathrm{Cu}
$$

Copper ion reduction rate is first order with respect to the reacting ions [4]. Thus the reaction presumably follows the rate law

$$
-\mathrm{V}_{\mathrm{s}}(\mathrm{dc} / \mathrm{dt})=\mathrm{kAc}
$$

where $V_{\mathrm{s}}$ is the volume of the solution in the reactor $\left(\mathrm{cm}^{3}\right), A$ is the exposed area $\left(\mathrm{cm}^{2}\right)$ of zinc sheet or rod, and $\mathrm{k}$ is the mass transfer coefficient $(\mathrm{cm} / \mathrm{s})$. Assuming that the copper ion concentration is negligibly low at the zinc metal-solution interface, integration of equation (2) yields the kinetic equation:

$$
\ln \left(\mathrm{C}_{\mathrm{o}} / \mathrm{C}\right)=\mathrm{kAt} / \mathrm{V}_{\mathrm{s}}
$$

where $\mathrm{C}_{\mathrm{o}}$ is the initial $\mathrm{Cu}^{2+}$ ion concentration, $\mathrm{ppm}$ and $\mathrm{C}$ is the concentration at time t.

Fig.1 shows the relation between $\log \left(\mathrm{C}_{\mathrm{o}} / \mathrm{C}\right)$ against time for cementation of copper in different copper sulphate concentrations from which the mass transfer coefficients were calculated as given in Table 1 .

Table 1. Values of $\mathrm{k}$ in different copper sulfate solutions at $25^{\circ} \mathrm{C}$.

\begin{tabular}{cccccc}
\hline $10^{2} \mathrm{k}, \mathrm{cm} / \mathrm{s}$ & 1.106 & 1.547 & 1.857 & 2.322 & 2.934 \\
\hline Concentration $(\mathrm{ppm})$ & 6.25 & 31.75 & 63.56 & 95.25 & 127.02 \\
\hline
\end{tabular}

Fig. 1 also indicates that cementation reaction is a first order reaction which was verified by other authors [3-14]. It is clear from Table 1 that the rate of mass 
transfer is increased by increasing concentration, i.e. cementation rate increases in the direction of precipitation of copper.

Fig. 2 shows an example of the relation between $\log \left(\mathrm{C}_{\mathrm{o}} / \mathrm{C}\right)$ versus time at different rpm and constant concentration of $\mathrm{CuSO}_{4}$ for the cementation of copper ions on rotating zinc rod. The rate of the cementation process was calculated, for reactions carried out at different initial copper ion concentrations and tabulated in Table 2. The value of the mass transfer coefficient increased with increasing the concentration of copper ions which is in agreement with reported results [5]. This may be attributed to the formation of a rough porous deposit which increases the surface area and decreases the diffusion path length due to the formation of small eddies in the laminar boundary layer [3].

Table 2. Effect of change of the initial concentration of $\mathrm{Cu}^{2+}$ ions and the speed of rotation on the mass transfer coefficient at $30^{\circ} \mathrm{C}$.

\begin{tabular}{cccc}
\hline \multirow{2}{*}{$\begin{array}{c}\text { Speed of } \\
\text { rotation } \\
(\mathrm{rpm})\end{array}$} & \multicolumn{3}{c}{ Concentration of $\mathrm{Cu}^{2+}$ ions $(\mathrm{ppm})$} \\
\cline { 2 - 4 } & 6.25 & 31.75 & 63.56 \\
\hline 50 & 3.70 & $10^{2} \mathrm{k} \mathrm{cm} / \mathrm{sec}$ \\
100 & 8.74 & 21.50 & 19.10 \\
200 & 14.10 & 28.05 & 35.30 \\
300 & 24.68 & 33.34 & 46.35 \\
400 & 32.20 & 40.20 & 53.51 \\
500 & 38.70 & 44.39 & 70.49 \\
\hline
\end{tabular}

Fig. 3 and 4 show the effect of stirring on the mass transfer coefficient in the presence of $\mathrm{CH}_{3} \mathrm{OH}$ and DMSO solvents. The data for $\mathrm{k}$, as a function of rpm are given in Table 3. The rate was found to increase with increasing the speed of rotation according to the relations $\mathrm{k} \alpha \mathrm{V}^{0.667}$ (for $\mathrm{CH}_{3} \mathrm{OH}$ ) and $\mathrm{k} \alpha \mathrm{V}^{0.35}$ (for DMSO). This indicates that the cementation reaction is a diffusion controlled reaction. However, if $\mathrm{k}$ is independent of stirring speed, then the reaction is chemically controlled. The exponent 0.35 agrees with the value 0.338 obtained for the cementation of copper on stationary zinc rod using nitrogen gas sparging as a measure of enhancing the rate of cementation [11]. The velocity exponent 
(0.667) in case of $\mathrm{CH}_{3} \mathrm{OH}$ is in agreement with the previously reported value (0.77) [15].

It is evident from Table 3 that the rate of cementation of copper on zinc is enhanced by stirring. This behaviour may be explained as follows: the higher the rotating speed, the higher the solution flow and the thinner the diffusion layer would be, besides, the solution in front of the rotating cylinder would receive a radial momentum. This radial mass transport would weaken and break up the boundary layer at the surface of the zinc rod which contributes to increase the cementation reaction.

Table 3. Effect of stirring on mass transfer coefficient at different solvents at $25^{\circ} \mathrm{C}$.

\begin{tabular}{lcccccc}
\hline Speed of rotation $(\mathbf{r p m})$ & $\mathbf{5 0}$ & $\mathbf{1 0 0}$ & $\mathbf{2 0 0}$ & $\mathbf{3 0 0}$ & $\mathbf{4 0 0}$ & $\mathbf{5 0 0}$ \\
\hline $10^{2} \mathrm{k}$ for $\mathrm{CH}_{3} \mathrm{OH}$ & 6.4 & 9.45 & 12.96 & 19.10 & 23.79 & 29.30 \\
\hline $10^{3} \mathrm{k}$ for $\mathrm{DMSO}$ & 15.11 & 20.12 & 23.10 & 26.43 & 29.51 & 36.56 \\
\hline
\end{tabular}

\section{Solvent effect}

\section{a- Protic solvent}

The variation of the physicochemical properties of the medium such as viscosity, density and dielectric constant, as a result of adding organic solvents, was expected to affect the rate of mass transfer process by affecting the diffusivity and activity of the metal ions. The rate of cementation of $\mathrm{Cu}^{2+}$ ions was studied in $\mathrm{CH}_{3} \mathrm{OH}-\mathrm{H}_{2} \mathrm{O}$ mixtures of different compositions $\left(0-30 \% \mathrm{v} / \mathrm{v} \mathrm{CH}_{3} \mathrm{OH}\right)$ at $25-40$ ${ }^{\circ} \mathrm{C}$.

Fig. 5 shows an example of the plots of $\log \left(\mathrm{C}_{\mathrm{o}} / \mathrm{C}\right)$ versus $t$ for the cementation of $\mathrm{Cu}^{2+}$ ions on rotating zinc rod in $\mathrm{CH}_{3} \mathrm{OH}-\mathrm{H}_{2} \mathrm{O}$ mixture. It is obvious that the reaction is first order as that occurring in Fig. 2 where no additive is added. The values of the mass transfer coefficient $\mathrm{k}$ were evaluated from the slopes of the plots of $\log \left(\mathrm{C}_{\mathrm{o}} / \mathrm{C}\right)$ versus $\mathrm{t}$ and are given in Table 4 . This table also encloses the values of the dielectric constant of the utilized solvent mixtures, estimated from those reported previously [14]. 
Table 4. Variation of mass transfer coefficient and dielectric constants with composition of $\mathrm{CH}_{3} \mathrm{OH}$ and with temperature.

\begin{tabular}{|c|c|c|c|c|c|c|c|c|c|}
\hline & \multicolumn{2}{|c|}{$\mathrm{t}=25^{\circ} \mathrm{C}$} & \multicolumn{2}{|c|}{$\mathrm{t}=30^{\circ} \mathrm{C}$} & \multicolumn{2}{|c|}{$\mathrm{t}=35^{\circ} \mathrm{C}$} & \multicolumn{2}{|c|}{$\mathrm{t}=40^{\circ} \mathrm{C}$} & \multirow{2}{*}{$\begin{array}{c}\Delta \mathrm{E} \\
\mathrm{KJ} \mathrm{mol}^{-1}\end{array}$} \\
\hline $\begin{array}{c}\text { Mole } \\
\text { fraction }\end{array}$ & $\begin{array}{c}10^{2} \mathrm{k} \\
\mathrm{cm} / \mathrm{sec}\end{array}$ & $\in$ & $\begin{array}{c}10^{2} \mathrm{k} \\
\mathrm{cm} / \mathrm{sec}\end{array}$ & $\in$ & $\begin{array}{c}10^{2} \mathrm{k} \\
\mathrm{cm} / \mathrm{sec}\end{array}$ & $\epsilon$ & $\begin{array}{c}10^{2} \mathrm{k} \\
\mathrm{cm} / \mathrm{sec}\end{array}$ & $\epsilon$ & \\
\hline 0.000 & 22.61 & 78.5 & 28.05 & 76.4 & 34.80 & 74.8 & 40.80 & 72.9 & $33.9 \pm 0.2$ \\
\hline 0.023 & 20.19 & 77.0 & 24.41 & 75.0 & 32.99 & 73.1 & 38.91 & 71.0 & $35.0 \pm 2.7$ \\
\hline 0.047 & 17.69 & 75.0 & 20.12 & 73.0 & 23.60 & 70.7 & 28.11 & 69.5 & $24.0 \pm 1.4$ \\
\hline 0.072 & 15.27 & 73.6 & 18.64 & 71.5 & 21.99 & 69.2 & 26.31 & 67.5 & $27.9 \pm 0.6$ \\
\hline 0.099 & 12.91 & 71.0 & 16.14 & 69.5 & 19.86 & 67.7 & 24.21 & 66.0 & $32.5 \pm 0.3$ \\
\hline 0.159 & 9.41 & 67.8 & 11.84 & 66.0 & 14.74 & 64.2 & 19.10 & 62.5 & $36.4 \pm 1.2$ \\
\hline
\end{tabular}

It was recognized from Table 4 that the values of the mass transfer coefficient decreased by increasing the mole fraction of $\mathrm{CH}_{3} \mathrm{OH}$. This can be attributed to the increase of the viscosity of the medium. The cementation process is known to be a diffusion controlled process whose rate is determined by the rate of mass transfer of $\mathrm{Cu}^{2+}$ ions to zinc surface. Therefore, the increase in the viscosity of the medium on adding $\mathrm{CH}_{3} \mathrm{OH}$, would decrease the diffusivity of $\mathrm{Cu}^{2+}$ ions with consequent decrease in the rate of cementation process. This can be understood from Stokes-Einstein equation:

$$
\mathrm{D}=(\mathrm{R} T / \mathrm{N})[1 /(6 \pi \eta \mathrm{r})]
$$

where $\mathrm{D}$ and $\mathrm{r}$ are the diffusion coefficient, $\mathrm{cm}^{2} / \mathrm{s}$, and radius of the electroactive species in the solution, respectively, $\eta$ is the viscosity coefficient of the solvent and $\mathrm{N}$ is Avogadro's number.

On the other hand, the addition of organic solvent may change the reactive species existing in solution by changing the composition of the solvation shell. Copper ions are solvated with water molecules to form $\left[\mathrm{Cu}\left(\mathrm{H}_{2} \mathrm{O}\right)_{4}\right]^{2+}$ in aqueous solution, alcohol molecules may replace some of the ligated water molecules and this would affect the mobility of copper ion [16], but in many cases this cannot be separated from the effect of the viscosity of the solvent. Another explanation for the decrease in the rate of cementation would be that the addition of alcohol has a marked effect on increasing the basicity of the medium. 


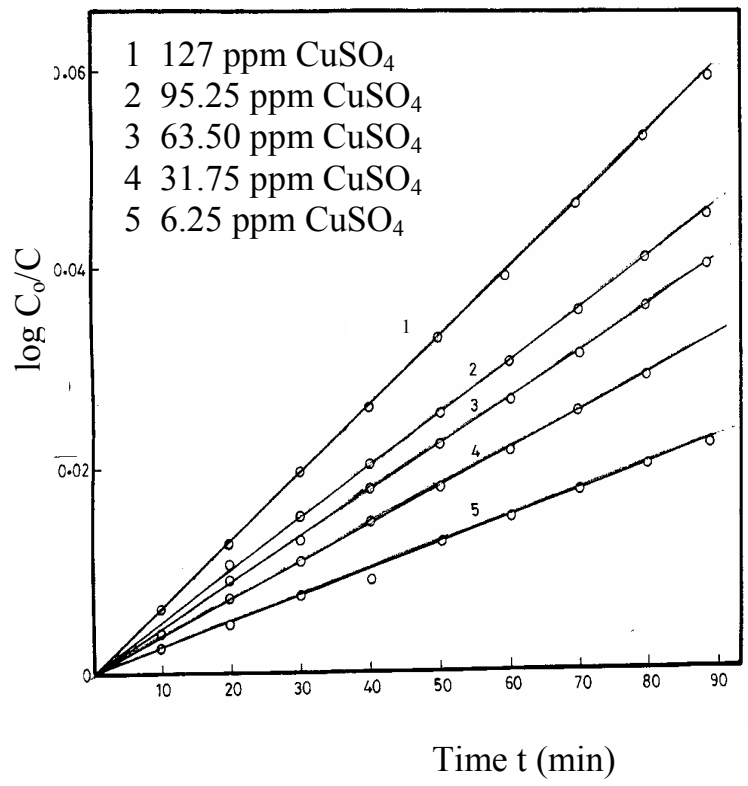

Figure 1. First order relation of cementation of different copper sulphate concentration at $25{ }^{\circ} \mathrm{C}$.

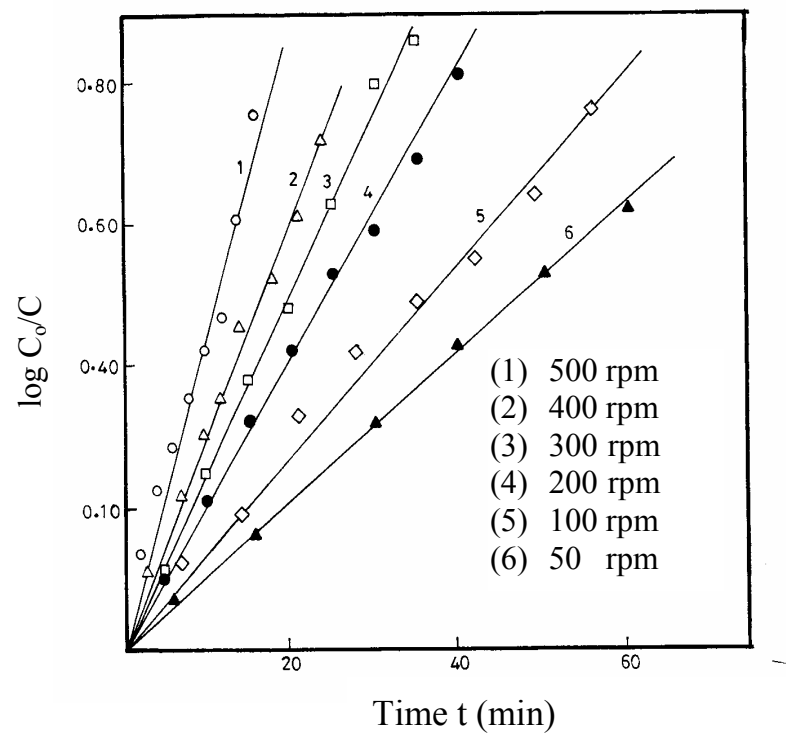

Figure 2. The relation between $\log \mathrm{C}_{\mathrm{o}} / \mathrm{C}$ and time at different speed of rotation at $30{ }^{\circ} \mathrm{C}$. 


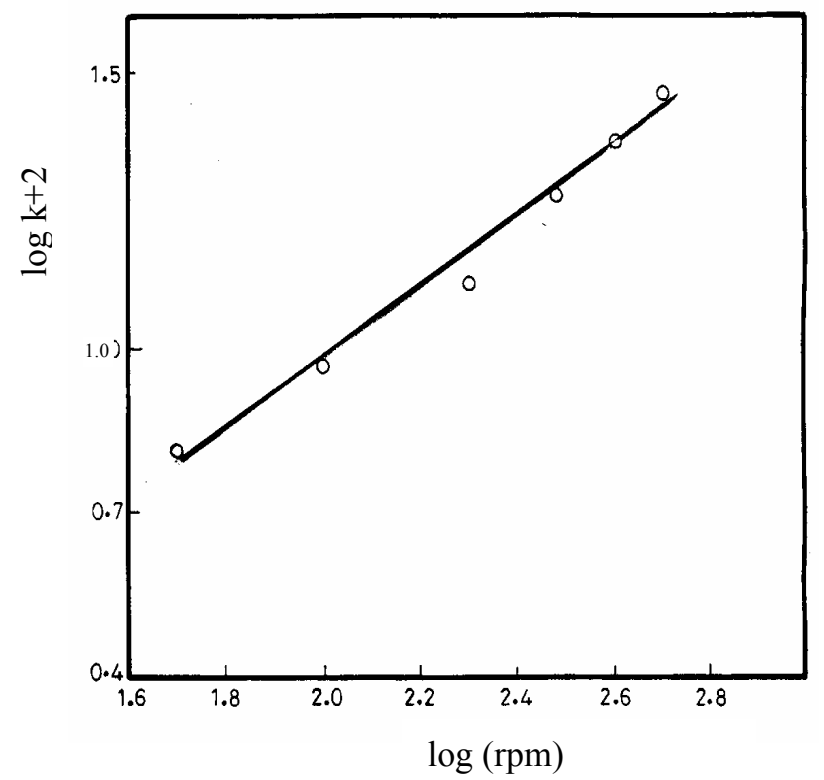

Figure 3. Effect of stirring on the mass transfer coefficient in presence of $20 \% \mathrm{CH}_{3} \mathrm{OH}$ at $25{ }^{\circ} \mathrm{C}$.

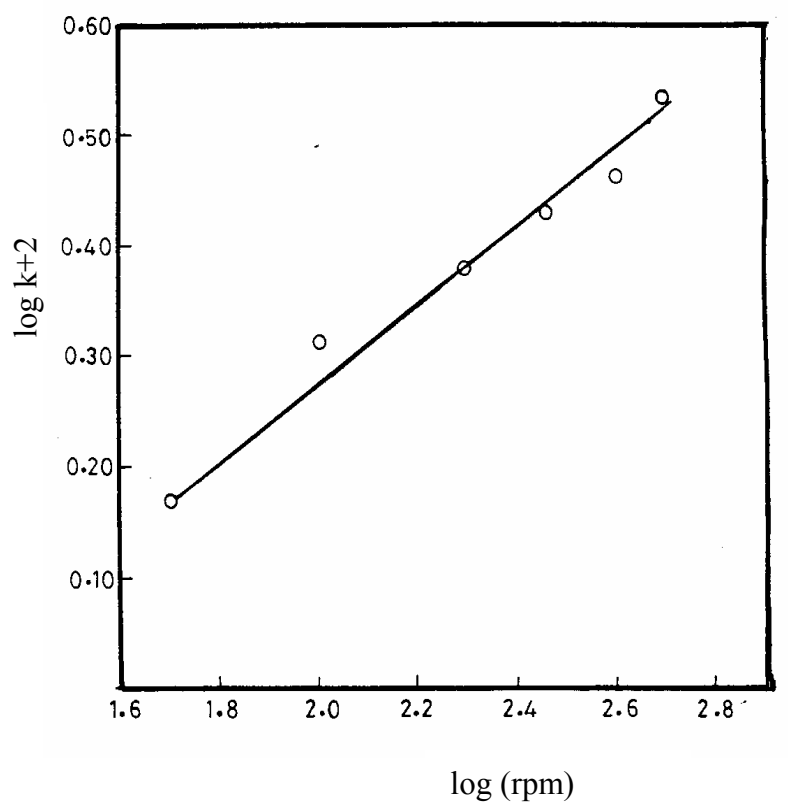

Figure 4. Effect of stirring on the mass transfer coefficient in presence of $20 \%$ DMSO at $25{ }^{\circ} \mathrm{C}$. 
The relative affinities of $\mathrm{H}_{2} \mathrm{O}$ or the non-aqueous component toward $\mathrm{Cu}^{2+}$ may be expected to arise from the relative solvating capacities of solvent dipoles exerted largely through hydrogen bond formation. The strength of hydrogen bonding should be largely guided by the relative charge densities on the oxygen and hydrogen charge centres of the isolated dipoles. The following picture may, to a first approximation, represent the isolated dipoles of $\mathrm{H}_{2} \mathrm{O}$ and $\mathrm{CH}_{3} \mathrm{OH}$, as has been indicated by Feakins [17].
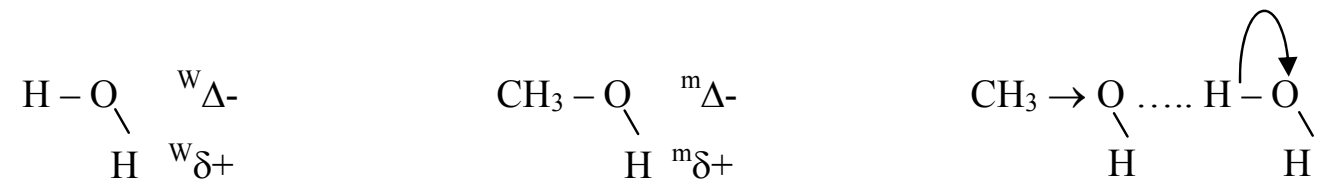

Owing to the inductive effect of the methyl group in $\mathrm{CH}_{3} \mathrm{OH}$, the negative charge density on the oxygen atom $\left({ }^{\mathrm{m}} \Delta_{-}\right)$is presumably somewhat greater than the corresponding quantity in water $\left({ }^{\mathrm{w}} \Delta_{-}\right)$. As a result, the protonic character of the $\mathrm{H}$ atom of $-\mathrm{OH}$ group in methanol $\left({ }^{\mathrm{m}} \delta+\right)$ is weaker than that in water $\left({ }^{\mathrm{w}} \delta+\right)$, i.e., ${ }^{\mathrm{m}} \Delta_{-}>{ }^{\mathrm{w}} \Delta_{-}$and ${ }^{\mathrm{m}} \delta+<{ }^{\mathrm{w}} \delta+$. Furthermore, $\mathrm{CH}_{3} \mathrm{OH}$ molecule is also expected to induce, in a water molecule hydrogen bonded to it, a negative charge on the hydrogen atom. These effects are likely to be relayed over several molecular diameters, rendering all molecules in $\mathrm{CH}_{3} \mathrm{OH}-\mathrm{H}_{2} \mathrm{O}$ mixtures more basic and less acidic than in pure water.

If $\mathrm{k}$ and $\mathrm{k}$ are the rate constants of cementation reaction in the absence and in the presence of organic solvent at definite concentration, the percentage inhibition can be calculated from the equation

$$
\% \text { inhibition }=\left(\mathrm{k}-\mathrm{k}^{\prime}\right) * 100 / \mathrm{k}
$$

Table 5 shows that the inhibition \% caused by protic solvents range from 10.70 to 74.08, depending on the type and concentration of alcohol used. A comparison of the results in $\mathrm{H}_{2} \mathrm{O}-\mathrm{CH}_{3} \mathrm{OH}$ with those obtained earlier [18] in various aqueous organic solvent systems at $25^{\circ} \mathrm{C}$ is given in Table 5 . The order of increasing the inhibition \% is as follows:

$$
\text { methanol }<\text { ethanol }<\text { ethylene glycol }<\text { glycerol }
$$


It is easy to predict that glycerol acts as a greater inhibitor while methanol is the smaller inhibitor. In case of ethanol the increase of the hydrocarbon chain causes an increase in the bulk of the groups than methanol which led to more inhibition to the cementation reaction by screening the surface of the metal from $\mathrm{Cu}^{2+}$. In the case of alcohols with two or more $\mathrm{OH}$ groups as in ethylene glycol and glycerol, the viscosity is high because the relatively large number of hydrogen bonds would require more energy to be ruptured in the formation of the activated state.

Table 5. Effect of concentration of solvents on the inhibition $\%$ in the mass transfer coefficient. $\left(\mathrm{CuSO}_{4}\right.$ concentration $\left.=31.75 \mathrm{ppm} ; \mathrm{rpm}=200 ; \mathrm{t}=25^{\circ} \mathrm{C}\right)$.

\begin{tabular}{lccccc}
\hline \multicolumn{1}{c}{$(\mathbf{V} / \mathbf{V}) \mathbf{\%}$} & $\mathbf{5}$ & $\mathbf{1 0}$ & $\mathbf{1 5}$ & $\mathbf{2 0}$ & $\mathbf{3 0}$ \\
\hline Methanol & 10.70 & 21.76 & 32.46 & 42.90 & 58.38 \\
\hline Ethanol & 18.35 & 29.01 & 36.09 & 44.40 & 61.52 \\
\hline Ethylene glycol & 29.19 & 39.50 & 50.38 & 59.40 & 69.48 \\
\hline Glycerol & 44.18 & 49.36 & 64.53 & 70.90 & 74.08 \\
\hline
\end{tabular}

\section{b- Dipolar aprotic solvents}

Dipolar aprotic solvents as DMSO have high dipole moment $\left(\mu_{25}=4.3\right.$ Debye) and high dielectric constant $\left(\epsilon_{25}=46.7\right)$. These solvents do not act as donors of hydrogen and the center of positive charge density is usually at a crowded site in the molecules. On the other hand the centre of negative charge density is usually on highly basic atom $\mathrm{O}, \mathrm{S}$ or $\mathrm{N}$ atom, which is highly exposed for intermolecular interaction with positive or acidic centers. Figs. 6 and 7 show an example of the plots of $\log \left(\mathrm{C}_{\mathrm{o}} / \mathrm{C}\right)$ versus time for the cementation of $\mathrm{Cu}^{2+}$ ions on a stationary zinc sheet (Fig. 6) and rotating zinc rod (Fig. 7) in $\mathrm{DMSO}_{2} \mathrm{H}_{2} \mathrm{O}$ mixtures at different temperatures and at constant $\mathrm{CuSO}_{4}$ concentration. The plots (Fig. 6) consist of two lines with different slopes indicating the existence of two parallel reactions, a slow reaction followed by a fast reaction. This behaviour is in agreement with the results found by Lee et al. [19]. They attributed the behaviour to the formation of a porous copper layer which increases the roughness of the surface. This leads to an increase in the mass transfer rate. The values of the mass 
transfer coefficient $\mathrm{k}$ were evaluated from the slopes of the plots and are given in Table 6.

Table 6. Variation of mass transfer coefficient with composition of DMSO and with temperature.

\begin{tabular}{|c|c|c|c|c|c|c|c|c|c|c|}
\hline Mole fraction & \multicolumn{2}{|c|}{0.0131} & \multicolumn{2}{|c|}{0.0273} & \multicolumn{2}{|c|}{0.0426} & \multicolumn{2}{|c|}{0.0594} & \multicolumn{2}{|c|}{0.0976} \\
\hline $\begin{array}{l}\text { Dielectric constant } \\
\text { at } 25^{\circ} \mathrm{C}\end{array}$ & \multicolumn{2}{|c|}{78.212} & \multicolumn{2}{|c|}{78.125} & \multicolumn{2}{|c|}{77.943} & \multicolumn{2}{|c|}{77.75} & \multicolumn{2}{|c|}{77.252} \\
\hline \multirow[t]{2}{*}{ Temperature } & $10^{5} \mathrm{k}$ & $10^{3} \mathrm{k}$ & $10^{5} \mathrm{k}$ & $10^{3} \mathrm{k}$ & $10^{5} \mathrm{k}$ & $10^{3} \mathrm{k}$ & $10^{5} \mathrm{k}$ & $10^{3} \mathrm{k}$ & $10^{5} \mathrm{k}$ & $10^{3} \mathrm{k}$ \\
\hline & (a) & (b) & (a) & (b) & (a) & (b) & (a) & (b) & (a) & (b) \\
\hline 25 & 3.12 & 23.10 & 2.90 & 21.15 & 2.56 & 18.11 & 1.86 & 14.12 & 1.43 & 11.21 \\
\hline 30 & 4.63 & 26.23 & 3.61 & 24.11 & 2.79 & 22.21 & 2.36 & 16.12 & 2.01 & 14.12 \\
\hline 35 & 6.01 & 30.11 & 5.24 & 28.21 & 4.39 & 24.21 & 3.05 & 18.12 & 2.70 & 16.01 \\
\hline 40 & 7.02 & 33.12 & 6.04 & 30.23 & 5.02 & 27.12 & 4.20 & 21.92 & 3.02 & 18.23 \\
\hline \multirow[t]{2}{*}{$\Delta \mathrm{E}^{*} \mathrm{KJ} \mathrm{mol}^{-1}$} & 41.9 & 18.9 & 40.0 & 19.1 & 38.4 & 20.2 & 41.9 & 22.3 & 39.5 & 24.7 \\
\hline & \pm 5.5 & \pm 0.8 & \pm 4.5 & \pm 1.8 & \pm 7.7 & \pm 2.6 & \pm 2.5 & \pm 2.0 & \pm 5.4 & \pm 2.5 \\
\hline
\end{tabular}

(a) values of mass transfer coefficient using stationary $\mathrm{Zn}$ sheet and (b) using rotating $\mathrm{Zn}$ cylinder.

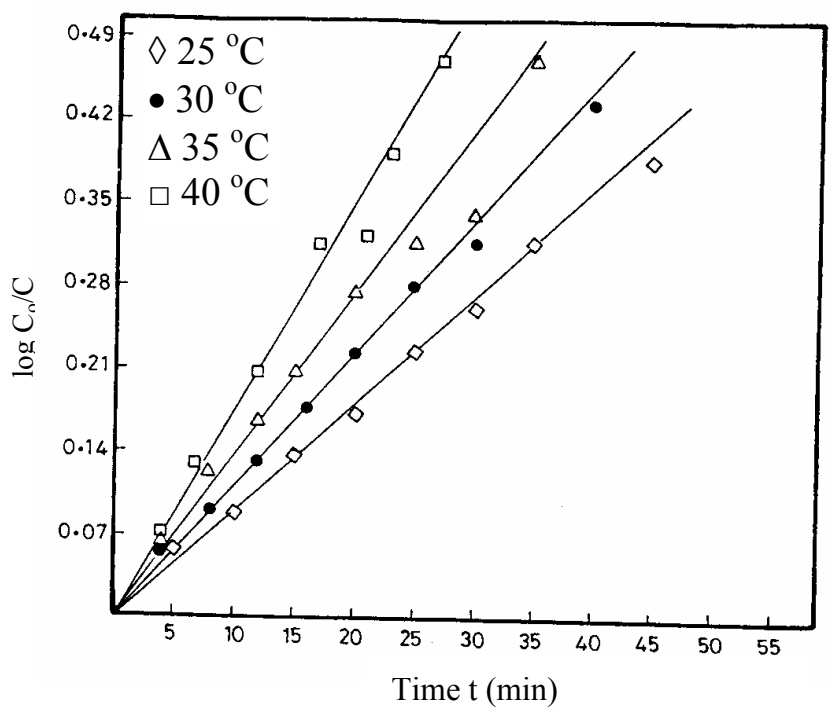

Figure 5. The relation between $\log \mathrm{C}_{\mathrm{o}} / \mathrm{C}$ and time in the presence of $20 \% \mathrm{CH}_{3} \mathrm{OH}$ at different temperatures and $200 \mathrm{rpm}$. 


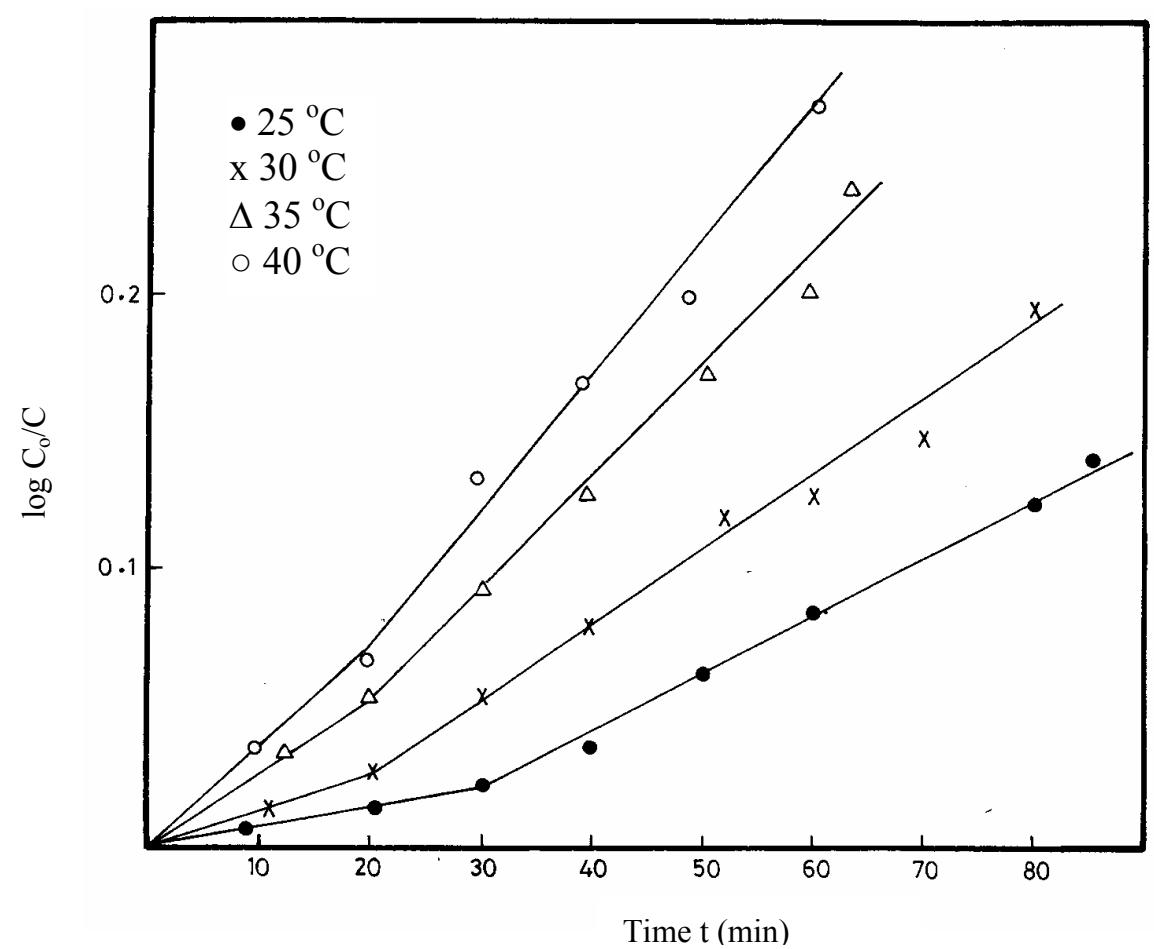

Figure 6. The relation between $\log \mathrm{C}_{0} / \mathrm{C}$ and time in the presence of $15 \%$ DMSO at different temperatures.

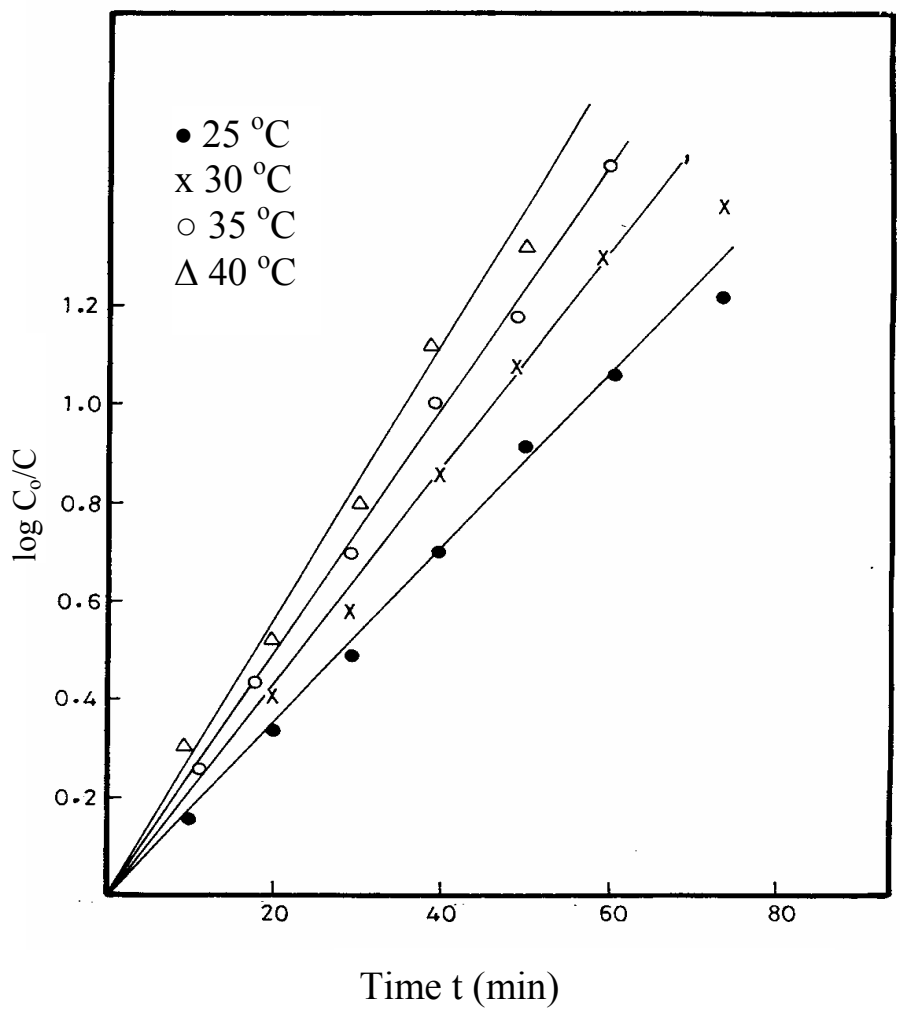

Figure 7. The relation between $\log \mathrm{C}_{\mathrm{o}} / \mathrm{C}$ and time in the presence of $20 \%$ DMSO at different temperatures. 
DMSO is usually good electron pair donor solvent and hence cation solvators. The strong basicity of DMSO- $\mathrm{H}_{2} \mathrm{O}$ mixture may be explained by considering the detailed charge distribution of the solvent molecule suggested by Feakins [17]. Sulphoxides as Lewis bases, normally co-ordinate through the oxygen atom.

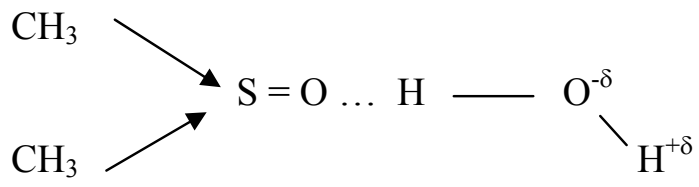

The basic centre for protonation will thus be the oxygen atom. The inductive effect of the two methyl groups, will enhance the polarization of the sulphoxide group resulting the increase of -ve charge on the oxygen atom of the DMSO molecule than that on the oxygen atom of the water molecule. In dipolar aprotic solvents, the reactivity of the cations is small compared to that in protic solvents, and the rate constants of reactions involving cations, as reactants, can increase when the solvent is changed from dipolar aprotic (Table 6) to protic (Table 4). According to this concept [20] we can predict that solvation of $\mathrm{Cu}^{2+}$ is higher in DMSO (as a reactant) than in $\mathrm{CH}_{3} \mathrm{OH}$. According to the basis of the so-called donor number DN (or donicity), this donor number can be considered as a measure of the degree of coordination interaction between EPD - solvents and the cations, and the increase in that number means an increase of solvent donicity and an increase of interaction between solvent and acceptor. The interaction is large with DMSO transition state relative to that of $\mathrm{CH}_{3} \mathrm{OH}$ leading to lower rates of copper cementation (Table 6). Inspection of Table 6, shows that an acceptable rate of metal removal is obtained by using conditions which are turbulent. The turbulence is introduced by the rotation of zinc rod and is further enhanced by the roughness of the rotated surface resulting from the growing metal centers. These particles are very effective turbulence promoters [21] and the mass transfer coefficient in such conditions can be higher than that in stationary condition.

\section{Effect of dielectric constant}

Tables $4-6$ show that, at a constant temperature, the mass transfer coefficient decreases as the dielectric constant of the medium decreases. This reveals that the 
ionizing power of the medium significantly affects the cementation process. As the dielectric constant increases the chance to form ion-pair decreases and hence the ionic mobility increases. Table 4 shows that as the temperature increases the dielectric constant decreases and the forces among the ions are greater, contrary to what expected, the rate of mass transfer increases. This is attributed to the fact that as the temperature increases the viscosity decreases, this leading to increase the rate of mass transfer. The effect of dielectric constant of $\mathrm{CH}_{3} \mathrm{OH}$ and DMSO on the cementation rate was investigated in the light of correlation of log $\mathrm{k}$ versus the reciprocal of the dielectric constant $(\in)$, whose values were interpolated from the literature $[14,22]$. The electrostatic treatment of reaction rate on the basis of point charge in a dielectric continuum suggested that the plots of log $\mathrm{k}$ against $\epsilon^{-}$ ${ }^{1}$, should be linear [23]. According to this theory the plot of $\log \mathrm{k}$ versus $1 / \in$, as shown in Fig. 8, reveals that a straight line with negative slope was obtained in both solvents.

\section{Thermodynamic treatment of the results}

The effect of temperature on the cementation of copper ions on rotating zinc rod was studied at $25,30,35$ and $40{ }^{\circ} \mathrm{C}$ for the reactions conducted in pure water and in different $\mathrm{CH}_{3} \mathrm{OH}-\mathrm{H}_{2} \mathrm{O}$ and DMSO- $\mathrm{H}_{2} \mathrm{O}$ media. The values of the energies of activation Ea* were calculated from the slopes of the linear Arrhenius plots of $\log \mathrm{k}$ versus $(1 / \mathrm{T})$ using the mean least squares method. These values are given in Tables 4 and 6 together with their standard deviation. The enthalpies $\Delta H^{*}$, entropies $\Delta \mathrm{S}^{*}$ and free energies $\Delta \mathrm{G}^{*}$ of activation were calculated using equations:

$$
\begin{gathered}
\Delta \mathrm{H}^{*}=\Delta \mathrm{E}^{*}-\mathrm{RT} \\
\Delta \mathrm{S}^{*} / \mathrm{R}=\ln \mathrm{A}-\ln (\mathrm{BTe} / \mathrm{h}) \\
\Delta \mathrm{G}^{*}=\Delta \mathrm{H}^{*}-\mathrm{T} \Delta \mathrm{S}^{*}
\end{gathered}
$$

where B is the Boltzmann's constant, $\mathrm{A}$ is an empirical constant, $\mathrm{T}$ is the absolute temperature, $\mathrm{R}$ is the gas constant, $\mathrm{h}$ is the Plank's constant and $\mathrm{e}$ is the electronic charge $(\mathrm{e}=2.7183)$. 


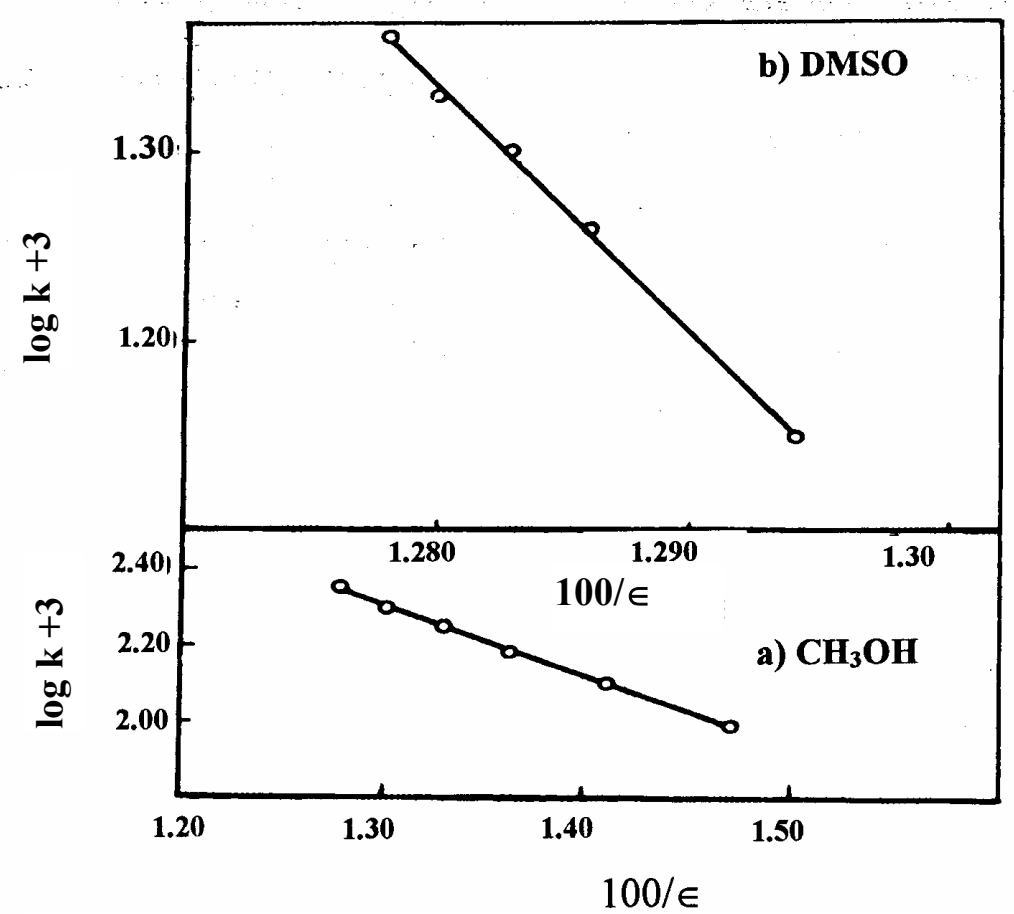

Figure 8. The relation between $\log \mathrm{k}$ and $1 / \epsilon$ for $\mathrm{CH}_{3} \mathrm{OH}-\mathrm{H}_{2} \mathrm{O}$ and DMSO- $\mathrm{H}_{2} \mathrm{O}$ mixtures at $25^{\circ} \mathrm{C}$.

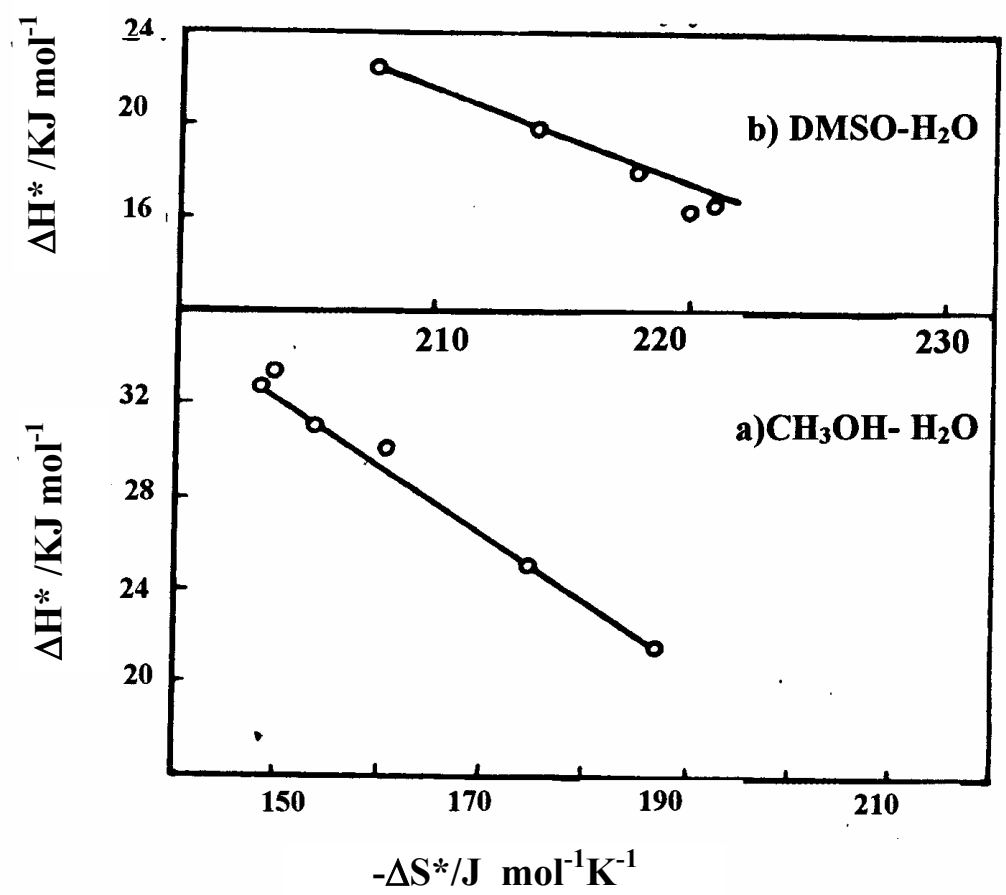

Figure 9. Variation of $\Delta \mathrm{H}^{*}$ with $\Delta \mathrm{S}^{*}$ at $25^{\circ} \mathrm{C}$. 


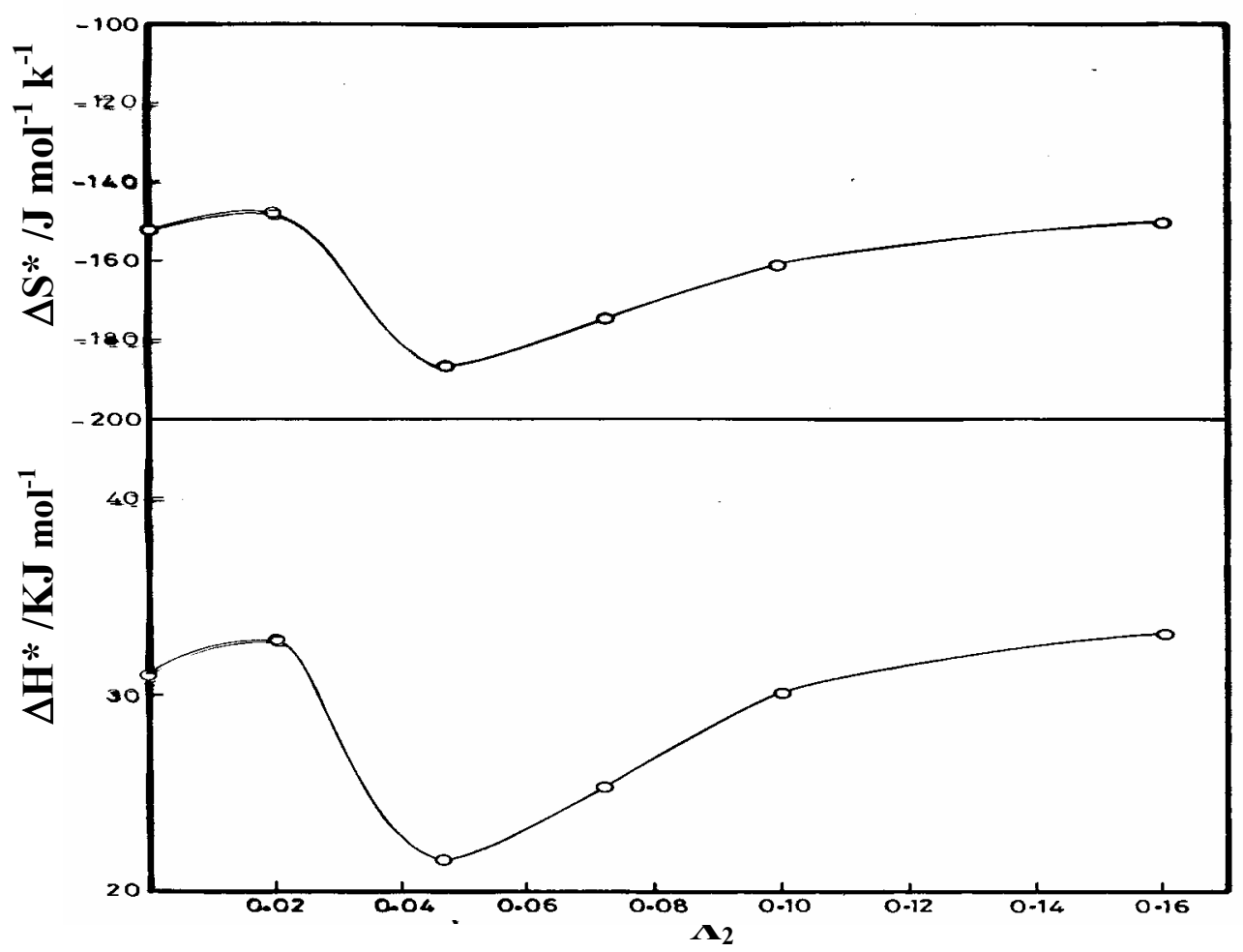

Figure 10. The Variation of $\Delta \mathrm{H}^{*}$ and $\Delta \mathrm{S}^{*}$ with mole fraction of methanol, for cementation reaction of copper.

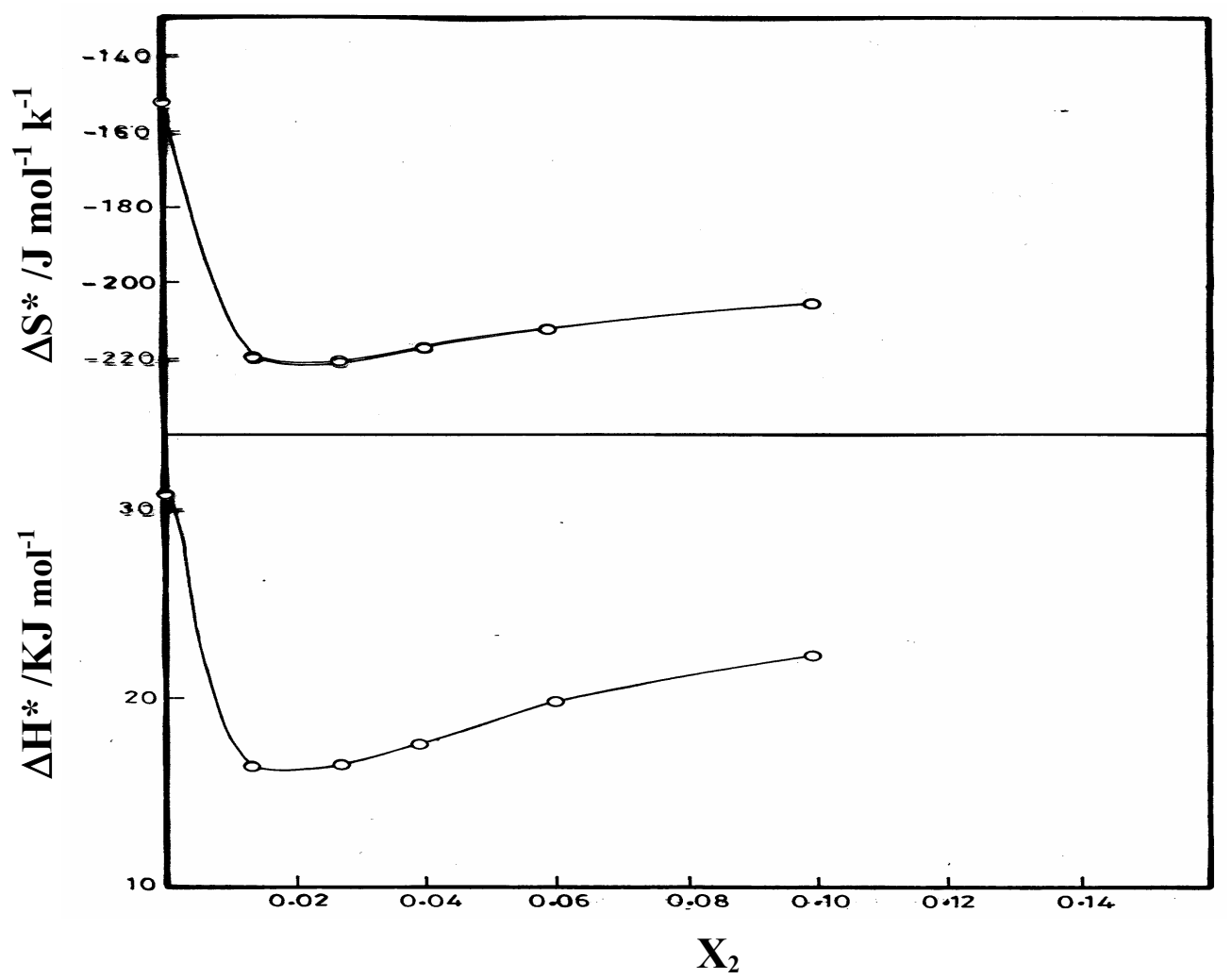

Figure 11. The Variation of $\Delta \mathrm{H}^{*}$ and $\Delta \mathrm{S}^{*}$ with mole fraction of DMSO, for cementation reaction of copper. 
Table 7. Variation of thermodynamic parameters of activation with solvent composition.

\begin{tabular}{cccc}
\hline mole fraction of $\mathbf{C H}_{\mathbf{3}} \mathbf{O H}$ & $\Delta \mathbf{H}^{*} / \mathbf{K J ~ m o l}^{\mathbf{1}}$ & $\Delta \mathbf{S}^{*} / \mathbf{J} \mathbf{~ m o l}^{-\mathbf{1}} \mathbf{k}^{-\mathbf{1}}$ & $\Delta \mathbf{G} * / \mathbf{K J ~ m o l}^{\mathbf{1}}$ \\
\hline 0.00 & $30.9 \pm 0.3$ & $-154 \pm 0.95$ & $76.7 \pm 0.6$ \\
\hline 0.023 & $32.8 \pm 2.7$ & $-148 \pm 9.0$ & $77 \pm 5.0$ \\
\hline 0.047 & $21.6 \pm 1.4$ & $-187 \pm 4.6$ & $77 \pm 3.0$ \\
\hline 0.072 & $25.4 \pm 0.6$ & $-175 \pm 2.0$ & $78 \pm 1.0$ \\
\hline 0.099 & $30.0 \pm 0.3$ & $-161 \pm 1.0$ & $78 \pm 0.6$ \\
\hline 0.159 & $33.9 \pm 1.2$ & $-150 \pm 4.0$ & $79 \pm 2.0$ \\
\hline
\end{tabular}

Table 7. (cont.)

mole fraction of DMSO

\begin{tabular}{cccc}
\hline 0.0131 & $16.5 \pm 0.8$ & $-221 \pm 2.7$ & $82.4 \pm 1.6$ \\
\hline 0.0273 & $16.6 \pm 1.8$ & $-221 \pm 6.0$ & $82.6 \pm 3.6$ \\
\hline 0.0426 & $17.7 \pm 2.6$ & $-219 \pm 8.4$ & $82.9 \pm 5.1$ \\
\hline 0.0594 & $19.8 \pm 1.9$ & $-214 \pm 6.3$ & $83.6 \pm 3.8$ \\
\hline 0.0976 & $22.2 \pm 2.5$ & $-208 \pm 8.3$ & $84.1 \pm 5.0$ \\
\hline
\end{tabular}

The values of the thermodynamic parameters are given in Table 7. The weak dependence of $\Delta \mathrm{G}^{*}$ on the composition of the solvent can be attributed to the general linear compensation between $\Delta \mathrm{H}^{*}$ and $\Delta \mathrm{S}^{*}$ (Fig. 9). The compensation effect may be attributed to the changes in water structure as a result of the addition of the organic solvent [24]. Table 7 shows that the free energy changes increase positively with decreasing the dielectric constant of the solvent. This shows that as the dielectric constant decreases more work is required to keep the ions apart and therefore, the precipitation of $\mathrm{Cu}^{2+}$ at the zinc rod is decreased as the dielectric constant decreases. There is less spontaneity and less cementation because of decrease discharge of $\mathrm{Cu}^{2+}$ at lower dielectric constant. Figs. 10 and 11 show the variation of $\Delta \mathrm{H}^{*}$ and $\Delta \mathrm{S}^{*}$ with the mole fraction of methanol and dimethyl sulphoxide.

Since the cementation reaction is a diffusion controlled process, as gained from the values of $E_{a}$, the thermodynamic parameters of activation are expected to be strongly affected by the variation of the properties of the medium. Previous theories $[24,25]$ described the structure of water to be effectively polymeric and has a unique well-developed hydrogen-bonded structure of low entropy. On mixing methanol two factors contribute to the values of $\Delta \mathrm{H}^{*}$ and $\Delta \mathrm{S}^{*}$, namely 
intercomponent bond formation and the bond breaking "depolymerization of water" with a disordering effect. According to this concept, when methanol and water are mixed with a small proportion of methanol, a contraction in volume occurs which reflects the strength of intercomponent attraction. This attraction would increase the viscosity of the medium and decrease the mobility of the cations. This can explain the increase in the values of $\Delta \mathrm{H}^{*}$ and $\Delta \mathrm{S}^{*}$ of the cementation process, as the mole fraction of methanol increases. According to previous studies [26], at $\mathrm{X}_{2}=0.047$, some kind of phase transformation may occur where alcohol molecules act as structure promoters. This increases the mobility of the cations and is considered to be the reason of the minimum in $\Delta \mathrm{H}^{*}$ $-\mathrm{X}_{2}$ and $\left(-\Delta \mathrm{S}^{*}\right)-\mathrm{X}_{2}$ curves (Fig. 10).

Inspection of Fig. 11 shows that both $\Delta \mathrm{H}^{*}$ and $\Delta \mathrm{S}^{*}$ have a broad minimum at (0.013-0.027). The electrostatic action transmitted through solvent molecules (field effect) govern these types of interaction. Previous studies[27] suggested that there is significant interaction of the positive charge on cation with surrounding water molecules. This interaction imposes a certain amount of order on the solvent about the cation making the entropy of cementation less negative as the number of alkyl groups increases. In the present investigation the charge of cations $\left(\mathrm{Cu}^{++}\right.$ion $)$imposes order on the surrounding solvent molecules which in turn interferes with internal rotation in alkyl groups, accordingly $\Delta \mathrm{S}^{*}$ become more negative relative to water solvent.

The plot of $\Delta \mathrm{H}^{*}$ versus $\Delta \mathrm{S}^{*}$ (Fig. 9) for different solvent composition at $25^{\circ} \mathrm{C}$ was found to be linear in both solvents. The isokinetic temperature $(\beta)$ was computed from the slopes of such plots. The $(\beta)$ values are 286 and $400 \mathrm{~K}$ for $\mathrm{CH}_{3} \mathrm{OH}-\mathrm{H}_{2} \mathrm{O}$ and DMSO- $\mathrm{H}_{2} \mathrm{O}$ mixture, respectively. In case of $\mathrm{CH}_{3} \mathrm{OH}-\mathrm{H}_{2} \mathrm{O}$ the value of $\beta(286 \mathrm{~K})$ is fairly close to the experimental temperature range studied (293-313 K) confirming the existence of compensation effect and indicating that the reaction is entropy controlled, while, in case of $\mathrm{DMSO}-\mathrm{H}_{2} \mathrm{O}, \beta$ values are much higher than the experimental temperature, indicating that the reaction is enthalpy control [6]. 


\section{Data correlation}

The dimensionless groups most often used in convective mass transfer are: Sherwood number $\mathrm{Sh}=\mathrm{kd} / \mathrm{D}$ where, $\mathrm{k}$ is the mass transfer coefficient or the rate constant. Schmidt Number $\mathrm{Sc}=(\gamma / \mathrm{D})$ where, $\gamma$ is kinematic viscosity, and Reynolds number $\operatorname{Re}=(\mathrm{Vd} / \gamma)$.

Forced convection takes place as a result of cylinder rotation. The thickness of the hydrodynamic boundary layer at the rotating cylinder and the diffusion layer are determined by the physical properties of the solution, the geometry of the system (cylinder diameter) and cylinder rotation speed. This picture leads to the equation

$$
\mathrm{k}=\mathrm{f}(\rho, \eta, \mathrm{D}, \mathrm{V}, \mathrm{d})
$$

where

$\mathrm{k}=$ mass transfer coefficient, $\mathrm{cm} / \mathrm{sec}$.

$\rho=$ density of bulk, $\mathrm{g} / \mathrm{cm}^{3}$.

$\eta=$ viscosity of bulk, $\mathrm{g} / \mathrm{cm} . \mathrm{s}$.

$\mathrm{D}=$ diffusion coefficient, $\mathrm{cm}^{2} \mathrm{sec}^{-1}$.

$\mathrm{V}=$ cylinder linear velocity $(\mathrm{V}=\omega \mathrm{r})$.

$\omega=$ angular velocity.

$\mathrm{d}=$ diameter of cylinder, $\mathrm{cm}$.

by using the method of dimensional analysis. The above equation can be written as

$$
\mathrm{Sh}=\mathrm{a} \mathrm{Sc}{ }^{\mathrm{b}} \mathrm{Re}^{\mathrm{c}}
$$

where $\mathrm{a}, \mathrm{b}$ and $\mathrm{c}$ are constants. Other equation was used

$$
\mathrm{Sh}=\mathrm{a} \mathrm{Sc}^{0.33} \mathrm{Re}^{\mathrm{c}}
$$

By plotting $\log \mathrm{Sh} / \mathrm{Sc}^{0.33}$ and $\log \mathrm{Re}$ a straight line was obtained; its slope gives constant $\mathrm{c}$ and interception gives the constant a. Figs. 12 and 13 show the overall mass transfer correlation for solvents used, from which, the data can be correlated by the following equations

$$
\text { For methanol } \mathrm{Sh}=0.019(\mathrm{Sc})^{0.33}(\mathrm{Re})^{0.93}
$$


For DMSO $\mathrm{Sh}=0.001(\mathrm{Sc})^{0.33}(\mathrm{Re})^{1.01}$

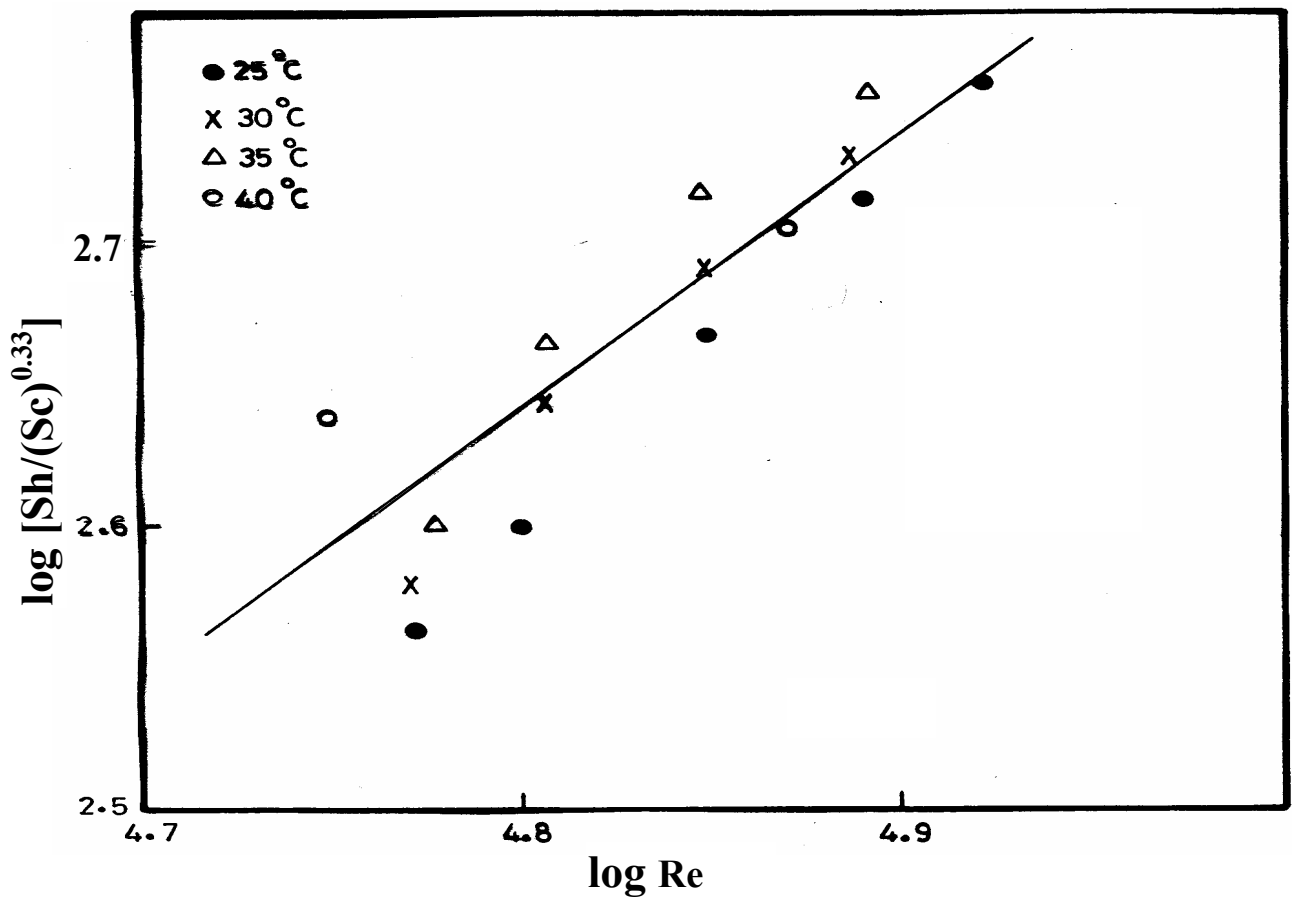

Figure 12. The overall mass transfer correlation in the presence of $\mathrm{CH}_{3} \mathrm{OH}$.

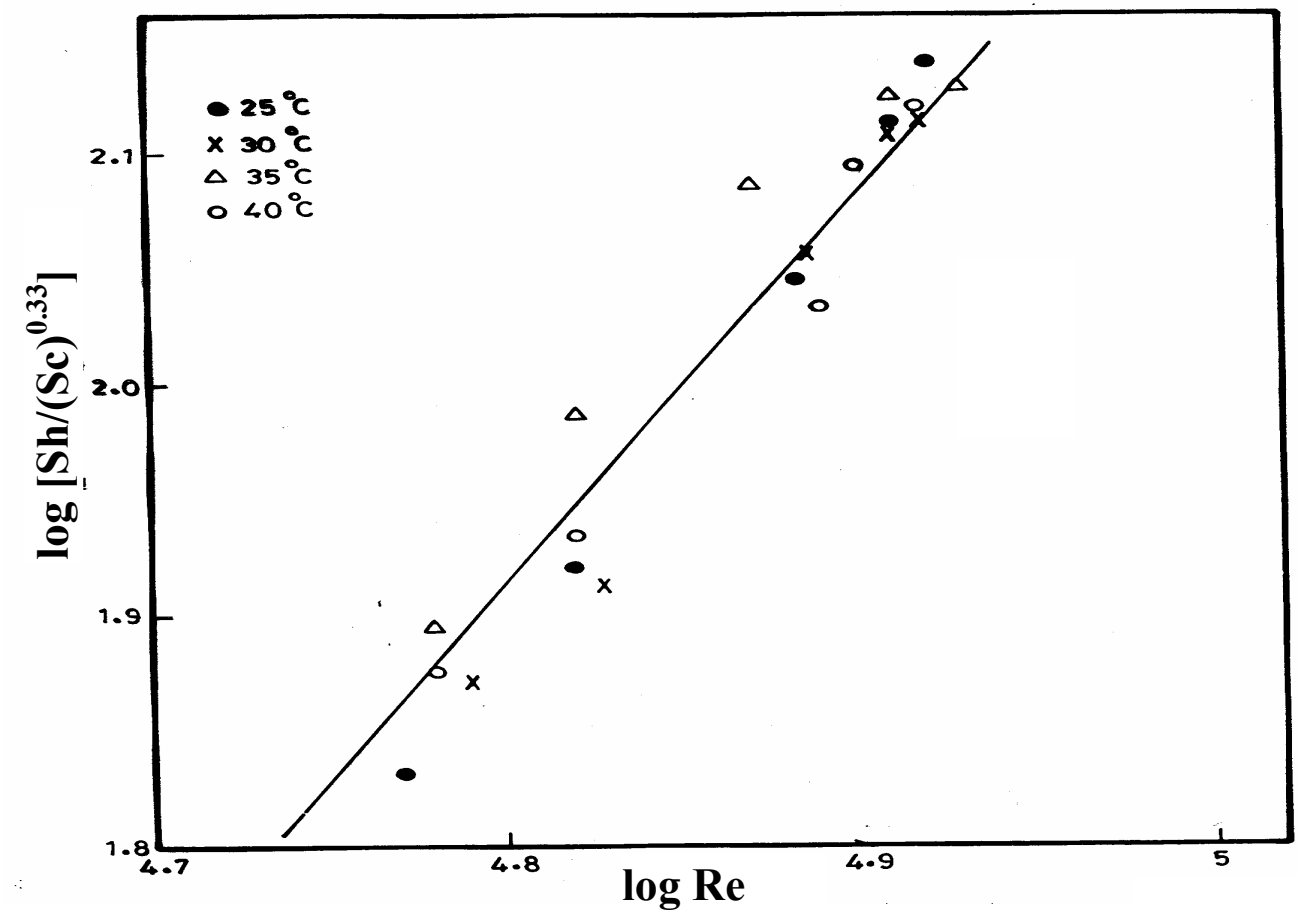

Figure 13. The overall mass transfer correlation in the presence of DMSO. 


\section{References}

1. A.K. Biswas and W.G. Davenport, "Extractive Metallurgy of Copper", Pergamon Press, New York (1979).

2. R.M. Nadkarni and M.E. Wadsworth, Trans. Met. Soc. AIME 239 (1967)1066.

3. P.H. Strickland, F. Lawson, Proc. Aust. Inst. Min. Met. 236 (1970) 25.

4. K. Young, C. Chen, Separation Science and Technology 27 (1992) 1259.

5. M.A. Zarraa, Hydrometallurgy 28 (1992) 423.

6. A.A. Zaghloul, G.M. El-Subruiti, A.M. Ahmed, J. Mater. Sci. Technol. Vol. 12 (1996).

7. S.A. Nosier, S.A. Sallam, Separation and Purification Technology 18 (2000) 93.

8. J.A. Sedzimir, Hydrometallurgy 64-3 (2002) 161.

9. A.M. Ismail, G.A. EL-Naggar, A.M. Ahmed, B. Electrochem. 17-9 (2001) 385 .

10. K. Young, W. Ming-Huan, S. Yung-shuen, Separation Science and Technology 37 (2002) 571.

11. S.A. Sallam, Egypt. J. Chem. 1-3 (2001) 111.

12. G.D. Sulka, M. Jasku, Hydrometallurgy 64-1 (2002) 13.

13. M.A. Gobshy, M.A. Fawzy, Metal., 2 (1987) 41.

14. M.EL-Batouti, A.I Kawana, A.A. Taha, Alex. Engineering J. 34-2 (1995) 59.

15. L. Sigrist, O. Dossenbach, N. Ibl, Int. J. Heat and Mass Transfer 22 (1979) 1393.

16. N. Tanaka, Electrochim. Acta 21 (1976) 701.

17. D. Feakins, "Physico-Chemical Processes in Mixed Aqueous Solvents", ed. F. Franks, Heine mann London, 17 (1967).

18. A. Harfoosh, A.M. Ahmed, Sh. A. EL-Shazly, H. Hammam, under publication.

19. E.C. Lee, F. Lawson, K.N. Han, Hydrometallurgy 37 (1978) .

20. E.A. Brand, E.S. Stern, J. Chem. Soc. 1948 (1976).

21. D.R. Gabe, F.C. Walsh, J. Appl. Electrochem. 13 (1983) 3. 
22. A.A. El-Harakany, A.M. Hafez, A.M. Khader, J. Electroanal. Chem. 132 (1985) 345.

23. K.J. Laidler, "Chemical Kinetics", $2^{\text {nd }}$ ed., McGraw-Hill, New York, 5 (1965).

24. F. Franks (Ed.) "Water, A Comprehensive Treatise”, Plenum Press, New York (1973).

25. A.J. Parker, Electrochim. Acta 21 (1976) 671.

26. F. Franks, D.J.G. Ives, Quarter. Rev 20 (1966) 1.

27. A.G. Evans, S.D. Hamann, Trans. Faraday Soc. 47 (1951) 34. 